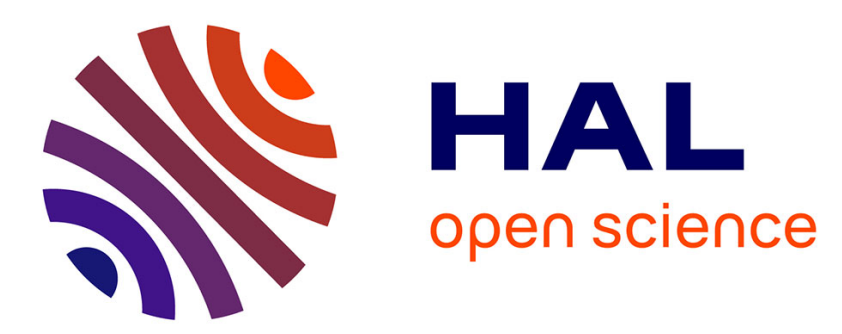

\title{
Trace Chemical Characterization of Liquid Drop by Fluorescence Detection of Absorption Edge Shifts using Total Reflection Support
}

\author{
K. Sakurai, A. Iida, H. Shintani
}

\section{- To cite this version:}

K. Sakurai, A. Iida, H. Shintani. Trace Chemical Characterization of Liquid Drop by Fluorescence Detection of Absorption Edge Shifts using Total Reflection Support. Journal de Physique IV Proceedings, 1997, 7 (C2), pp.C2-713-C2-714. 10.1051/jp4:1997216 . jpa-00255223

HAL Id: jpa-00255223

https://hal.science/jpa-00255223

Submitted on 1 Jan 1997

HAL is a multi-disciplinary open access archive for the deposit and dissemination of scientific research documents, whether they are published or not. The documents may come from teaching and research institutions in France or abroad, or from public or private research centers.
L'archive ouverte pluridisciplinaire HAL, est destinée au dépôt et à la diffusion de documents scientifiques de niveau recherche, publiés ou non, émanant des établissements d'enseignement et de recherche français ou étrangers, des laboratoires publics ou privés. 


\title{
Trace Chemical Characterization of Liquid Drop by Fluorescence Detection of Absorption Edge Shifts using Total Reflection Support
}

\author{
K. Sakurai, A. Iida* and H. Shintani** \\ National Research Institute for Metals, 1-2-1 Sengen, Tsukuba, Ibaraki 305, Japan \\ * Photon Factory, 1-1 Oho, Tsukuba, Ibaraki 305, Japan \\ ** National Institute of Health Sciences, 1-18-1 Kamiyoga, Setagaya, Tokyo 158, Japan
}

\begin{abstract}
An analytical technique to investigate the chemical state of trace metals in a small amount of sample has been proposed. While the principle for distinguishing the chemical state is based on well known X-ray spectroscopic phenomena, i.e., chemical shifts of the absorption edges, a total reflection mirror has been employed as a support to enhance the signal to background ratio through the reduction of scattering X-ray background. The present paper describes the details of the analytical procedure and shows the successful results of the near edge absorption spectrum of trace iron $(\sim \mathrm{mM})$ in a wet liquid drop $(\sim \mu \mathrm{l})$ measured in $3 \sim 5 \mathrm{~min}$. The feasibility of the application to biomedical science is also mentioned.
\end{abstract}

\section{INTRODUCTION}

Investigation of trace metals is quite important in materials as well as in biomedical sciences [1]. Not only the identification/determination of metals but also information on the chemical state is significant. However, when the quantity of the sample is limited, and the sample is only a liquid drop or fine particles from some biological tissue, it becomes extremely difficult to analyze its trace components through conventional chromatography based on chemical separation. Xray fluorescence detection of the absorption edge shifts is highly sensitive and is a powerful technique for characterizing trace metals in the order of ppm in a bulk sample [2,3]. In addition, it can be applied to the near-surface analysis of a mirrorpolished sample [4]. There are two ways of extending the technique to the small quantity sample; one uses a small-size SR beam [5] and the other employs a total reflection sample support. In the present paper, the latter approach has been described with special emphasis on the analysis of a liquid drop.

\section{EXPERMMENTAL PROCEDURE}

A total reflection mirror has been extensively employed as a sample support since the first successful X-ray florescence experiment by Yoneda et al. in 1971 [6]. While the main focus of the modern grazing incidence studies is often placed on the investigation of the mirror itself, this technique enables the trace determination of very small quantity of solution dropped and dried on the mirror. The advantage is a very high signal to background ratio which is principally due to the extremely small penetration to the mirror substrate and the availability of a big solid angle of a $\mathrm{Si}(\mathrm{Li})$ detector. Accordingly, sensitivity is very high and is less than $\mathrm{ppb}[7,8]$. In the present research, the measurement of absorption edge position has been combined with a total reflection sample support, in order to measure the chemical state of trace metals in a small amount of sample. The ease of supporting is one of the advantages in extending the application to many type of samples.

The experiment was carried out using SR at the Photon Factory on beam line 4A. Figure 1 shows the schematics of the experimental setup, which is essentially the same as for the grazing incidence X-ray fluorescence study [9]. SR beams were monochromatized by a $\mathrm{Si}(111)$ double crystal sagittal focusing monochromator. The energy resolution was about $1 \mathrm{eV}$ at the absorption edge of iron. The intensities of incident and reflected X-rays were measured by two ionization chambers. $A$ mirror-polished silicon wafer was used as a sample support, and the optical alignment was optimized by the translational/rotational motion of the sample stage. Two layouts were considered for the arrangement of a $\mathrm{Si}(\mathrm{Li}) \mathrm{detector}$, which measures $\mathrm{K} \alpha$ fluorescent $\mathrm{X}$-rays from the metal of interest. For most cases, it was set at 90 deg. to the incident $\mathrm{X}$-rays with an inclination of about $10 \mathrm{deg}$. from the horizontal plane. This has the advantage of reducing the scattering background from the liquid drop itself by using linear polarization of SR. However, when the sample is not a wet solution, and the scattering is relatively weak, it was much better to set the detector perpendicular to the sample, because the distance between the detector can be set at the closest position (typically a few $\mathrm{mm}$ ) to boost the signal. In both cases, an aperture was placed in front of the $\mathrm{Si}(\mathrm{Li})$ detector to view only the sample.

The measurement procedure is as follows: (1) Tune the energy at the post edge of the metal of interest. (2) Align a silicon mirror below the critical angle so that X-rays are totally reflected. (3) Measure an XRF spectrum. This is for a blank evaluation to confirm the metal of interest is not observed as an impurity. (4) Drop a solution by a micro pipette, typically 0.5 


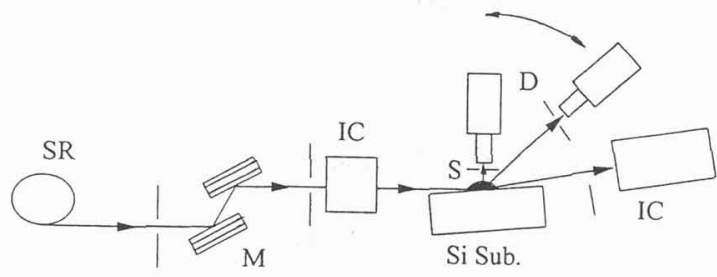

Figure 1 Schematic drawings of the experimental setup; SR: storage ring, $\mathrm{M}$ : monochromator; $\mathrm{IC}$ : ionization chambers for incident and reflected X-rays; S: sample; $\mathrm{D}$ : $\mathrm{Si}(\mathrm{Li})$ detector.

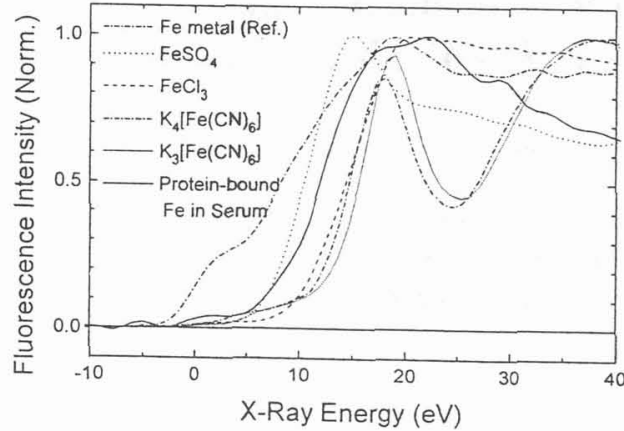

Figure 2 Near edge absorption spectrum of trace iron in a liquid drop obtained by X-ray fluorescence detection at the total reflection condition.

$\sim 3 \mu \mathrm{l}$. (5) Quickly scan the incident X-ray energy around the absorption edge. The energy range is typically $30 \sim 50 \mathrm{eV}$, and the measuring time is $3 \sim 5 \mathrm{~min}$ in total. Read out the chemical shifts of the absorption edge.

\section{RESULTS AND DISCUSSION}

Figure 2 shows the near edge absorption spectrum of diluted iron solution $(5 \mathrm{mM}, 3 \mu \mathrm{l})$ of the standard materials. The measurement was done for a wet drop. Fluorescent X-ray intensity abruptly increases as the incident energy crosses the absorption edge, and exibits different behavior. It is confirmed that the edge shift of $\mathrm{FeCl}_{3}$ ( $\mathrm{Fe}(\mathrm{III})$ ) is larger than that of $\mathrm{FeSO}_{4}(\mathrm{Fe}(\mathrm{II})$ ). This means that trace $\mathrm{Fe}(\mathrm{II})$ and $\mathrm{Fe}(\mathrm{III})$ in the small quantity sample can be distinguished. In addition, the conspicuous pre-edge structure of $\mathrm{K}_{3}\left[\mathrm{Fe}(\mathrm{CN})_{6}\right]$ or $\mathrm{K}_{4}\left[\mathrm{Fe}(\mathrm{CN})_{6}\right]$ would be feasible for identification besides the use of chemical shift of the absorption edge. It has been found that the practical lower limit is around $0.1 \mathrm{mM}$ in our case. Though the scattering background from a usual support or a cell for a solution sample degrades the sensitivity critically, the present procedure has improved it to almost the same standard as a relatively thin case in bulk analysis [2]. One should notice that fluorescence intensity increases as a liquid drop dries out. This is because of the change in absorption loss of the fluorescence in the drop, and therefore a quick measurement is essential for a wet drop sample.

The present procedure was applied to donor horse serum (ICN Biomedicals, Inc, USA) centrifuged $(10,000 \mathrm{~g}, 30 \mathrm{~min}$ at $4 \mathrm{C}$ ). It has been found that protein-bound iron (in the order of sub $\mathrm{mM}$ ) has been found to be in the mixed state of $\mathrm{Fe}(\mathrm{II})$ and Fe(III) as shown in Fig.2, but free iron (in the order of $\mu \mathrm{M}$ [1]) could not detected because of still insufficient sensitivity. The study on the selenium in uremia and serum is now in progress from a clinical point of view. When the material of interest is in a dried state and the volume of a residue is extremely small, it was found that the perpendicular detector geometry is effective. The sensitivity in the absolute amount was at least 1000 times better than that of a wet drop in the present experiment. Such a big difference is essentially due to the difference in the ratio of the signal to scattering background from the sample itself, and this suggests the significance of the improvement of the detector system and optimization of the geometry.

\section{SUMMARY}

It has been demonstrated that a total reflection sample support works well for the measurement of chemical shifts of absorption edges by X-rsay fluorescence detection. The chemical state of trace metals in a small wet drop has been successfully analyzed. Potential feasibility for biomedical application will become clearer, when the sensitivity is further improved by future advances of the detection system (e.g., wavelength dispersive spectrometer to eliminate the scattering background as much as possible) as well as the use of 3rd generation SR. This work was performed under the approval of the Photon Factory Program Advisory Committee (Proposal No.96G-235).

\section{References}

1. for example, Clinical Chemistry Special issue: "Trace elements in clinical chemistry", 21(1975) No.4.; "Gradwohl's Clinical laboratory Methods and Diagnosis", edited by A.C.Sonnenwirth and L.Jarett (The C.V. Mosby Company, St. Louis, 1980).

2. K.Sakurai, A.Iida and Y.Gohshi, Anal. Sci. 4(1988) 37; K.Sakurai, A.Iida, M.Takahashi and Y.Gohshi, Jpn. J. Appl. Phys. 27 (1988)

L1768.

3. I.Nakai and A.lida, Adv. in X-Ray Anal. 35B(1992) 1307.

4. K.Sakurai and A.Iida, Adv. in X-Ray Anal. 33(1990) 205.

5. A.lida and T.Noma, Nucl. Instrum. \& Methods B82(1993) 129.

6. Y.Yoneda and T.Horiuchi, Rev. Sci. Instrum. 42(1971) 1069

7. A.lida, A. Yoshinaga, K. Sakurai and Y. Gohshi, Anal. Chem. 58(1986) 394

8. A.Prange and H.Shwenke, Adv. in X-Ray Anal. 35B(1992) 899

9. K.Sakurai and A.Iida , Adv. in X-Ray Anal. 39(1996) (in press). 